\title{
Targeting the PI3K/AKT/mTOR pathway overcomes the stimulating effect of dabrafenib on the invasive behavior of melanoma cells with acquired resistance to the BRAF inhibitor
}

\author{
SIMONA CAPORALI ${ }^{1}$, ESTER ALVINO ${ }^{2}$, PEDRO MIGUEL LACAL $^{1}$, \\ LAURETTA LEVATI $^{1}$, GIORGIO GIURATO ${ }^{3,4}$, DOMENICO MEMOLI ${ }^{3}$, ELISABETTA CAPRINI ${ }^{1}$, \\ GIAN CARLO ANTONINI CAPPELLINI ${ }^{5}$ and STEFANIA D'ATRI ${ }^{1}$ \\ ${ }^{1}$ Laboratory of Molecular Oncology, Istituto Dermopatico dell'Immacolata-IRCCS, Rome; \\ ${ }^{2}$ Institute of Translational Pharmacology, National Council of Research, Rome; ${ }^{3}$ Laboratory of Molecular \\ Medicine and Genomics and ${ }^{4}$ Genomix4Life Srl, University of Salerno, Baronissi (SA); ${ }^{5}$ Department of \\ Oncology and Dermatological Oncology, Istituto Dermopatico dell'Immacolata-IRCCS, Rome, Italy
}

Received December 17, 2015; Accepted April 19, 2016

DOI: $10.3892 /$ ijo.2016.3594

\begin{abstract}
BRAF inhibitors (BRAFi) have proven clinical benefits in patients with BRAF-mutant melanoma. However, acquired resistance eventually arises. The effects of BRAFi on melanoma cell proliferation and survival have been extensively studied, and several mechanisms involved in acquired resistance to the growth suppressive activity of these drugs have been identified. Much less is known about the impact of $\mathrm{BRAFi}$, and in particular of dabrafenib, on the invasive potential of melanoma cells. In the present study, the BRAF-mutant human melanoma cell line A375 and its dabrafenib-resistant subline A375R were analyzed for invasive capacity, expression of vascular endothelial growth factor receptor (VEGFR)-2, and secretion of VEGF-A and matrix metalloproteinase (MMP)-9, under basal conditions or in response to dabrafenib.
\end{abstract}

Correspondence to: Dr Stefania D'Atri, Laboratory of Molecular Oncology, Istituto Dermopatico dell'Immacolata-IRCCS, Via dei Monti di Creta 104, 00167 Rome, Italy

E-mail: s.datri@idi.it

Abbreviations: BRAFi, BRAF inhibitors; BSA, bovine serum albumin; CM, complete medium; DMSO, dimethyl sulfoxide; ECL, enhanced chemiluminescence; ECM, extracellular matrix; EGFR, epidermal growth factor receptor; IC, inhibitory concentration; MMP, matrix metalloproteinase; MTT, 3-(4,5-dimethylthiazol2-yl)-2,5-diphenyltetrazolium bromide; siRNA, small interfering RNA; PBS, phosphate-buffered saline; RTK, receptor tyrosine kinase; SDS-PAGE, sodium dodecyl sulphate-polyacrylamide gel electrophoresis; SEM, standard error of the mean; SNV, single nucleotide variation; STAT3, signal transducers and activators of transcription-3; TBST, Tris-buffered saline/Tween-20; VEGFR, vascular endothelial growth factor receptor

Key words: melanoma, BRAF, dabrafenib, GSK2126458A, bevacizumab, drug resistance, invasion
The consequences of inhibiting the PI3K/AKT/mTOR pathway on A375R cell responses to dabrafenib were also evaluated. We found that A375R cells were more invasive and secreted higher levels of VEGF-A and MMP-9 as compared with A375 cells. Dabrafenib reduced invasiveness, VEGFR-2 expression and VEGF-A secretion in A375 cells, whereas it increased invasiveness, VEGF-A and MMP-9 release in A375R cells. In these latter cells, the stimulating effects of dabrafenib on the invasive capacity were markedly impaired by the anti-VEGF-A antibody bevacizumab, or by AKT1 silencing. A375R cells were not cross-resistant to the PI3K/mTOR inhibitor GSK2126458A. Moreover, this inhibitor given in combination with dabrafenib efficiently counteracted the stimulating effects of the BRAFi on invasiveness and VEGF-A and MMP-9 secretion. Our data demonstrate that melanoma cells with acquired resistance to dabrafenib possess a more invasive phenotype which is further stimulated by exposure to the drug. Substantial evidence indicates that continuing BRAFi therapy beyond progression produces a clinical benefit. Our results suggest that after the development of resistance, a regimen combining BRAFi with bevacizumab or with inhibitors of the PI3K/AKT/mTOR pathway might be more effective than BRAFi monotherapy.

\section{Introduction}

Mutations in the BRAF oncogene are present in over $50 \%$ of cutaneous melanomas (1), with the vast majority of the mutations leading to the V600E substitution in the BRAF oncoprotein and the constitutive activation of the MAPK/ERK signaling pathway, which is crucial for melanoma growth, survival and invasion (reviewed in refs. 2 and 3). In patients with BRAFmutant melanoma, inhibition of the oncogenic BRAF kinase with vemurafenib or dabrafenib, or its downstream effector kinases MEK1/2 with trametinib, yields objective response rates of 50-60 and of 20-30\%, respectively, and significantly prolongs progression-free and overall survival with respect to dacarbazine chemotherapy (4-6). Moreover, the combination 
of dabrafenib and trametinib is well tolerated and associated with a higher response rate and improved disease-free and overall survival as compared with single-agent therapy (7-9).

Despite the impressive initial responses to BRAF inhibitors (BRAFi), the long-term efficacy of these compounds is limited by the emergence of drug resistance (reviewed in refs. 10-13). Multiple mechanisms of acquired resistance to BRAFi have been described, involving both reactivation of MAPK/ERK signaling and/or activation of alternative pro-survival pathways. Restoration of MAPK/ERK signaling in the presence of BRAFi has been shown to occur by activating mutations in NRAS, MAP $2 K 1$ or MAP $2 K 2$, loss of $N F 1, B R A F^{V 600 E}$ amplification, overexpression of the CRAF or COT1 kinases, as well as by the expression of splice variants of $B R A F^{V 600 E}$ (10-13). Alternative mechanisms of secondary resistance to BRAFi mainly involve alterations leading to upregulation of the $\mathrm{PI} 3 \mathrm{~K} / \mathrm{AKT} / \mathrm{mTOR}$ signaling axis. In this regard, mutations in AKT1, AKT3, PIK3CA, PIK3CG, PIK3R2 and PHLPP1, $P T E N$ loss as well as overexpression and/or activation of the receptor tyrosine kinases (RTKs) platelet-derived growth factor receptor $\alpha$ and $\beta$, insulin-like growth factor 1 receptor, fibroblast growth factor receptor-3, and epidermal growth factor receptor (EGFR), have been reported (10-16). Notably, RTK signaling can also bypass mutant BRAF and activate ERK via RAS $(10,14,15)$.

Although a large body of experimental data is available on the effects of BRAFi on melanoma proliferation and survival, and on the molecular mechanisms involved in acquired resistance to the growth-suppressive effects of these agents, much less is known about the impact of BRAFi on melanoma cell migration and invasion. In this regard, Halaban et al (17) showed that while vemurafenib inhibited migration of BRAF-mutant melanoma cells, it increased that of BRAF wild-type cells, as a result of drug-induced CRAF activation. Girotti et al (18) demonstrated that BRAF-mutant melanoma cells with acquired resistance to PLX4720, a drug structurally related to vemurafenib (19), were more invasive, both in vitro and in vivo, than the corresponding drug-sensitive counterparts as a consequence of hyperactivation of the EGFR-SRC family kinase-signal transducers and activator of transcription 3 (STAT3) signaling pathway. Increased invasiveness of BRAFmutant melanoma cells that had been rendered resistant to the BRAFi SB590885 was reported by Vultur et al (20), who also showed activation of the STAT3 pathway in these cells under basal conditions and upon exposure to SB590885. Similarly, Zubrilov et al (21) found that in vitro induction of vemurafenib resistance in BRAF-mutant melanoma cells was associated with increased potential for metastasis. The vemurafenibresistant cells showed, indeed, enhanced migratory and adherence functions, higher expression levels of several genes involved in promotion of metastasis and increased capacity to form lung and liver micro-metastasis in nude mice. SanchezLaorden et al (22) demonstrated that PLX4720 stimulated the invasive capacity of RAS-mutant melanoma cells by a mechanism involving activation of the MEK/ERK pathway, increased expression and secretion of IL-8 and induction of protease-dependent invasion. Moreover, increased levels of $I L-8$ mRNA and similar responses to PLX4720 were observed by these authors in BRAF-mutant melanoma cells which had developed resistance to the drug. On the contrary, vemurafenib was reported to exert a moderate inhibition of the in vitro invasive activity of a BRAF ${ }^{\mathrm{V} 600 \mathrm{E}} / \mathrm{NRAS}$ wild-type melanoma cell line showing primary resistance to the antiproliferative effects of the drug as a consequence of MET amplification and activation (23).

To the best of our knowledge, no data are presently available concerning the effects of dabrafenib on the metastatic potential of BRAF-mutant melanoma cells. In the present study we, therefore, evaluated the effect of dabrafenib on the in vitro invasive capacity of melanoma cells sensitive or with acquired resistance to the growth suppressive effects of the drug. We also investigated whether inhibition of the PI3K/AKT/mTOR signaling pathway could modulate the effects of dabrafenib on the invasive behavior of the resistant cells.

\section{Materials and methods}

Cell cultures. The human melanoma cell line A375 was purchased from the European Collection of Cell Cultures (Salisbury, UK) and cultured in BioWhittaker ${ }^{\mathrm{TM}}$ RPMI-1640 medium (Lonza, Verviers, Belgium) supplemented with $10 \%$ fetal bovine serum (FBS; Sigma-Aldrich, St. Louis, MO, USA), $2 \mathrm{mM}$ BioWhittaker ${ }^{\mathrm{TM}}$ L-glutamine (Lonza), and $50 \mu \mathrm{g} / \mathrm{ml}$ BioWhittaker $^{\mathrm{TM}}$ gentamicin (Lonza) (hereafter referred to as complete medium, CM). The A375R subline with acquired resistance to dabrafenib was generated by growing the parental A375 cells in gradually increasing concentrations of dabrafenib (from $1 \mathrm{nM}$ up to $1.5 \mu \mathrm{M}$ ) over a period of 4 months. After selection, A375R cells were maintained in CM supplemented with $1.5 \mu \mathrm{M}$ dabrafenib.

Drugs, chemicals and antibodies. Dabrafenib (GSK2118436A) and GSK2126458A were dissolved in dimethyl sulfoxide (DMSO; Sigma-Aldrich) at a final concentration of 1.92 and $1 \mathrm{mM}$, respectively. Both drugs were stored as stock solutions at $-80^{\circ} \mathrm{C}$ and diluted in $\mathrm{CM}$ just before use.

3-(4,5-dimethylthiazol-2-yl)-2,5-diphenyltetrazolium bromide (MTT) was purchased from Sigma-Aldrich, dissolved at a concentration of $5 \mathrm{mg} / \mathrm{ml}$ in Gibco $^{\mathrm{TM}}$ phosphate-buffered saline (PBS; Invitrogen, Thermo Fisher Scientific, Waltham, MA, USA) and stored at $4^{\circ} \mathrm{C}$.

For western blot analysis, the following rabbit polyclonal antibodies were used: anti-human ERK1/2 (GTX17942; GeneTex, Irvine, CA, USA), anti-human phospho-ERK1/2 (Thr185/Tyr187) (44-680G; Invitrogen), anti-human $\beta$-tubulin (sc-9104; Santa Cruz Biotechnology, Inc., Santa Cruz, CA, USA), anti-vascular endothelial growth factor receptor-2 (VEGFR-2) (sc-6251; Santa Cruz Biotechnology), anti-human AKT (9272; Cell Signaling Technology, Inc., Beverly, MA, USA) and anti-human phospho-AKT (Ser473) (9271; Cell Signaling Technology).

Reagents for sodium dodecyl sulphate-polyacrylamide gel electrophoresis (SDS-PAGE) were all purchased from Bio-Rad Laboratories, Inc. (Hercules, CA, USA).

DNA extraction and whole exome sequencing. DNA extraction from A375 and A375R cell lines was performed using the DNeasy Blood \& Tissue kit (Qiagen GmbH, Hilden, Germany) according to the manufacturer's protocol, and sheared with a Bioruptor sonicator (Diagenode, Liege, 
Belgium). DNA libraries were prepared and captured using the SureSelect Human All Exon kit (50 Mb; Agilent Technologies, Santa Clara, CA, USA) according to the manufacturer's instructions. DNA libraries were sequenced by Genomix4life S.r.l., (Baronissi, Salerno, Italy) on Illumina NextSeq 500 platform (Illumina, San Diego, CA, USA) with 100-bp paired-end reads.

Exome sequence analysis. Sequence reads were mapped to the reference human genome assembly hg19 using BurrowsWheeler Aligner (BWA-MEM) version 0.7.12 (24). PCR duplicates were removed using Picard 1.130 (http://broadinstitute.github.io/picard). The Genome Analysis Toolkit (GATK) version 3.4 was used for realignment of insertions and deletions, quality recalibration and variant calling (25). Then, to create a sub-selection of high-quality single nucleotide variations (SNVs), a series of filtering options was applied, including minimum read depth of $8 \mathrm{x}$, SNV call quality score above 30 , and non-reference allele frequency above $20 \%$. Variants were annotated with information from RefGenes using wANNOVAR web-based tool (26).

Chemosensitivity assay. A375 and A375R cells were suspended in CM, seeded (50 $\mu \mathrm{l} /$ well) into BD Falcon ${ }^{\mathrm{TM}}$ 96-well plates (BD Biosciences, Bedford, MA, USA) and allowed to adhere at $37^{\circ} \mathrm{C}$ in a $5 \% \mathrm{CO}_{2}$ atmosphere for $18 \mathrm{~h}$. Graded amounts of dabrafenib or GSK2126458A were then added to the cells in $50 \mu 1$ of CM. As a control, A375 and A375R cells were treated with DMSO alone. The plates were incubated at $37^{\circ} \mathrm{C}$ for five days and cell proliferation was then evaluated by the MTT assay, as previously described (27). Three replica wells were used for each group. Drug concentration producing 50\% inhibition of cell growth (i.e. $\mathrm{IC}_{50}$ ), was calculated on the regression line in which absorbance values at $595 \mathrm{~nm}$ were plotted against the logarithm of drug concentration. In a different set of experiments, A375R cells, plated as described above, were incubated with DMSO alone, $100 \mathrm{nM}$ dabrafenib, $20 \mathrm{nM}$ GSK2126458A or a combination of the two drugs for 5 days and then assayed for proliferation using the MTT assay.

Cell treatment for western blot analysis and invasion assay. A375 and A375R cells were suspended in CM, seeded into $\mathrm{BD} \mathrm{Falcon}^{\mathrm{TM}} 10$-cm-dishes (BD Biosciences) and allowed to adhere at $37^{\circ} \mathrm{C}$ in a $5 \% \mathrm{CO}_{2}$ atmosphere for $18 \mathrm{~h}$. Thereafter, dabrafenib $(100 \mathrm{nM})$ or DMSO alone was added to the cultures and the dishes incubated at $37^{\circ} \mathrm{C}$ for additional 6 or $48 \mathrm{~h}$. In a different set of experiments, A375R cells, plated as described above, were incubated with DMSO alone, $100 \mathrm{nM}$ dabrafenib, $20 \mathrm{nM}$ GSK2126458A or a combination of the two drugs for $48 \mathrm{~h}$. At the end of the incubation period, melanoma cells were processed for western blot analysis or tested for their ability to invade the extracellular matrix (ECM) in vitro.

Western blot analysis. For analysis of ERK1/2, phosphorylated ERK1/2, AKT and phosphorylated AKT expression, control and drug-treated cells were recovered from culture, washed and total cellular extracts were prepared as described previously (28). For analysis of VEGFR-2 expression, melanoma cells were left in the culture dishes, washed, lysed directly in SDS sample buffer $(50 \mathrm{mM}$ Tris- $\mathrm{HCl} \mathrm{pH} 6.8,100 \mathrm{mM}$ dithiothreitol, 2\% SDS, $0.1 \%$ bromophenol blue and 10\% glycerol) and then boiled for $5 \mathrm{~min}$. Proteins per sample $(15 \mu \mathrm{g})$ were run on a $6 \%$ (VEGFR-2) or 12\% SDS-polyacrylamide gels, transferred to nitrocellulose membranes (Amersham Biosciences, Buckinghamshire, UK) and blocked with 5\% non-fat milk in Tris-buffered saline supplemented with $0.1 \%$ Tween-20 (TBST) for $1 \mathrm{~h}$ at room temperature. The membranes were then incubated in the same solution, or in TBST containing $5 \%$ bovine serum albumin (BSA), overnight at $4^{\circ} \mathrm{C}$ with primary antibodies at the following dilutions: antiERK1/2, anti-phospho-ERK1/2, anti-AKT and anti- $\beta$-tubulin 1:1,000; anti-phospho-AKT 1:500; anti-VEGFR-2 1:200. The anti- $\beta$-tubulin antibody was used as an internal standard for loading. Immunodetection was carried out using appropriate horseradish peroxidase-linked secondary antibodies and enhanced chemiluminescence (ECL) or ECL Prime (phosphoAKT) detection reagents (Amersham Biosciences). Where indicated, film was scanned on a GS-710 Calibrated Imaging Densitometer and analyzed by means of Quantity One Software Version 4.1.1 (Bio-Rad Laboratories).

Invasion assay in Boyden chambers. This assay was performed as previously described (29). Briefly, control and drugtreated melanoma cells were removed from culture, washed, suspended in invasion medium $(1 \mu \mathrm{g} / \mathrm{ml}$ heparin/0.1\% BSA in RPMI-1640) and loaded ( $2 \times 10^{5}$ cells) into the upper compartment of Boyden chambers equipped with $8-\mu \mathrm{m}$ pore diameter polycarbonate filters (Nuclepore, Whatman Inc., Clifton, NJ, USA) coated with $20 \mu \mathrm{g}$ of BD Matrigel ${ }^{\mathrm{TM}}$ Basement Membrane Matrix (BD Biosciences, hereafter referred to as Matrigel). Invasion medium or, where indicated, invasion medium containing $20 \mathrm{ng} / \mathrm{ml}$ VEGF-A (ImmunoTools, Friesoythe, Germany) was added to the lower compartment of the chambers. For each experimental condition, three Boyden chambers were set up. After incubation of the Boyden chambers at $37^{\circ} \mathrm{C}$ in a $5 \% \mathrm{CO}_{2}$ atmosphere for $4 \mathrm{~h}$, the filters were removed from the chambers and the cells were fixed in ethanol for $5 \mathrm{~min}$ and stained in $0.5 \%$ crystal violet for $15 \mathrm{~min}$. The cells from the upper surface of the filter were removed by wiping with a cotton swab and the migrated cells, attached to the lower surface of the filters, were counted under the microscope. Twelve microscopic fields (magnification, x200), randomly selected on triplicate filters, were scored for each experimental condition.

In a set of experiments, invasion assays were performed in the presence of the anti-human VEGF-A monoclonal antibody bevacizumab $(5 \mu \mathrm{g} / \mathrm{ml})$ (Avastin; Roche, Welwyn Garden City, UK) or the corresponding control $\mathrm{IgG}_{1}$ immunoglobulins (MAB002; R\&D Systems, Minneapolis, MN, USA). A375R cells were pre-incubated with the antibodies for $30 \mathrm{~min}$ at room temperature in a rotating wheel. The cells were then loaded in the Boyden chambers without removing the antibodies.

Three-dimensional spheroid invasion assay. A375 and A375R spheroids were generated as described by Naber et al (30) with minor modifications. Briefly, melanoma cells were suspended $\left(4 \times 10^{4}\right.$ cells $\left./ \mathrm{ml}\right)$ in $\mathrm{CM}$ containing $0.24 \%$ methylcellulose (Sigma-Aldrich) and seeded (100 $\mu \mathrm{l} /$ well) into non-adhesive, round-bottom 96-well plates (Corning Inc., Corning, NY, USA). Plates were centrifuged at $1250 \mathrm{x}$ g for $90 \mathrm{~min}$ and 
then incubated at $37^{\circ} \mathrm{C}$ in a $5 \% \mathrm{CO}_{2}$ atmosphere for $18 \mathrm{~h}$ to allow the cells to organize into three-dimensional spheroids (one spheroid in each well). Spheroids were then harvested and individually embedded between two layers of Matrigel as previously described (31) with minor modifications. Briefly, $50 \mu \mathrm{l}$ of Matrigel diluted in RPMI-1640 medium $(4 \mu \mathrm{g} / \mathrm{ml})$, were added to the wells of a flat-bottom 96-well plate, that was then incubated at $37^{\circ} \mathrm{C}$ for $15 \mathrm{~min}$ to let the Matrigel solidify. Melanoma spheroids, suspended in $100 \mu \mathrm{l}$ of Matrigel diluted in invasion medium $(4 \mu \mathrm{g} / \mathrm{ml})$, were then seeded in the Matrigel-precoated plate (one spheroid/well, five replicates). After a 30 -min incubation at $37^{\circ} \mathrm{C}$ to allow Matrigel polymerization, spheroids were overlaid with $100 \mu \mathrm{l}$ of invasion medium and the plate incubated at $37^{\circ} \mathrm{C}$ for $48 \mathrm{~h}$. At the end of incubation, images of the invading spheroids were taken using a Leica inverted microscope and a Canon digital camera PowerShot G5.

Transient transfection with small interfering RNA (siRNA) targeting AKT1 and drug treatment of the transfected cells. Oligonucleotide siRNA targeting AKT1 (CUCACAGCC CUGAAGUACU) (siAKT) and the corresponding scramble oligonucleotide (GAUCCUAUAUUCGGUUAGU) (siCTRL) to be used as a control were purchased from Sigma-Proligo (The Woodlands, TX, USA).

A375R cells were suspended in CM without antibiotics, seeded into $\mathrm{BD}$ Falcon ${ }^{\mathrm{TM}}$ 6-well plates (BD Biosciences), allowed to adhere at $37^{\circ} \mathrm{C}$ in a $5 \% \mathrm{CO}_{2}$ atmosphere for $18 \mathrm{~h}$, and then transfected with $10 \mathrm{nM}$ siAKT or siCTRL using Lipofectamine $^{\mathrm{TM}}$ RNAiMAX reagent (Invitrogen) according to the manufacturer's protocol. Twenty-four hours after transfection, the cells were incubated with $100 \mathrm{nM}$ dabrafenib or DMSO alone. After $48 \mathrm{~h}$ of culture, the cells were collected and processed for western blot analysis or tested for ability to invade the ECM.

Evaluation of VEGF-A and matrix metalloproteinase-9 (MMP-9) secretion. A375 and A375R cells were suspended in $\mathrm{CM}$, seeded into BD Falcon $10 \mathrm{~cm}$-dishes (BD Biosciences) and allowed to adhere at $37^{\circ} \mathrm{C}$ in a $5 \% \mathrm{CO}_{2}$ atmosphere for $18 \mathrm{~h}$. Thereafter, A375 cells were incubated with DMSO alone or $100 \mathrm{nM}$ dabrafenib, whereas A375R were incubated with DMSO alone, $100 \mathrm{nM}$ dabrafenib, $20 \mathrm{nM}$ GSK2126458A or a combination of the two drugs. After $48 \mathrm{~h}$ of drug exposure, culture supernatants were collected, centrifuged at $600 \mathrm{xg}$ for $10 \mathrm{~min}$ to remove cells in suspension and debris, and frozen at $-20^{\circ} \mathrm{C}$ until use. Cells were detached with a solution of $1.5 \mathrm{mM}$ EDTA in PBS and counted to determine the total number of cells in the culture. Quantification of the VEGF-A amount in the culture supernatants was performed as previously described (32). For MMP-9 evaluation, culture supernatants were concentrated at least 5-fold in Centriplus concentrators (Amicon, Beverly, MA, USA). The amount of active MMP-9 in the culture supernatants was then determined using the Quantikine ELISA Human MMP-9 immunoassay (R\&D Systems) according to the manufacturer's protocol, and calibrated against a standard curve. The amount of VEGF-A and MMP-9 was normalized to the number of total cells counted in each culture at the time of supernatant collection.
Statistical analysis. Statistical significance among different values of drug $\mathrm{IC}_{50}$, different number of ECM invading cells and different levels of VEGF-A and MMP-9 secretion, was assessed using two-sided Student's t-test analysis.

\section{Results}

Generation and characterization of the A375R subline with acquired resistance to dabrafenib. To generate a cellular model of acquired resistance to dabrafenib, the human melanoma cell line A375, which harbors the $\mathrm{BRAF}^{\mathrm{V} 600 \mathrm{E}}$ mutation and is highly sensitive to the growth suppressive effects of BRAF inhibitors, was cultured with gradually increasing concentrations of dabrafenib until a subline (i.e. A375R) able to growth in the presence of $1.5 \mu \mathrm{M}$ of the drug was obtained. This concentration of dabrafenib corresponds to the peak plasma concentration reported for patients treated with the drug at the recommended dose of $150 \mathrm{mg}$ BID (33).

A375 and A375R cells were initially analyzed for sensitivity to the antiproliferative effects of dabrafenib, and for expression of total and phosphorylated ERK1/2, either under basal conditions or following a 6-h exposure to $100 \mathrm{nM}$ of the drug. MTT assays, performed after five days of cell culture with graded concentrations of dabrafenib, revealed that the A375R subline was 10,000-fold more resistant to the growth inhibitory effect of this drug than the parental cell line (Fig. 1A). A375R cells also expressed higher basal levels of phosphorylated ERK1/2 as compared with A375 cells (Fig. 1B). Moreover, while dabrafenib, as expected, markedly downregulated the level of phosphorylated ERK1/2 in A375 cells, it further increased it in the drug-resistant subline (Fig. 1B).

Previous studies have shown that melanoma cells with acquired resistance to the BRAFi vemurafenib, PLX4720 or SB590885 possess a more invasive phenotype (18,20-22), whereas no data are available regarding the metastatic potential of dabrafenib-resistant cells. Therefore, we evaluated the ability of A375 and A375R cells to spontaneously invade the ECM using the Boyden chamber assay. The results illustrated in Fig. 1C show that the dabrafenib-resistant A375R cells were $\sim 2$-fold more invasive than the dabrafenib-sensitive A375 cells.

The invasive behavior of A375 and A375R cells was also investigated using an invasion assay based on Matrigelembedded spheroids, that mimics the three-dimensional tumor architecture and incorporates components of the ECM (34). Consistent with results obtained in Boyden chamber assays A375R spheroids invaded into Matrigel to a higher extent as compared with parental A375 cells (Fig. 1D).

Finally, to investigate whether reactivation of the MAPK/ERK pathway in A375R cells could be dependent on mutations in HRAS, KRAS, NRAS, MAP $2 K 1, M A P 2 K 2$ or on $N F 1$ loss, whole exome sequencing was performed in both A 375 and A375R cell lines. No mutations in the three $R A S$ genes or in $M A P 2 K 1$ and $M A P 2 K 2$, and no loss of $N F 1$ were detected in A375 and A375R cells.

Dabrafenib impairs invasiveness and VEGF-A secretion in A375 cells, whereas it stimulates these functions in A375R cells. We previously showed that an autocrine loop sustained by the interaction of VEGF-A with VEGFR-2 promoted melanoma cell ability to migrate and invade the ECM in vitro (35). 
A

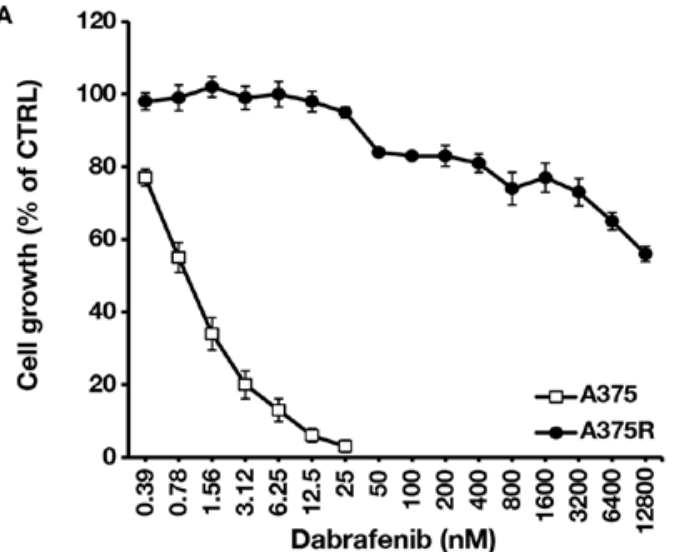

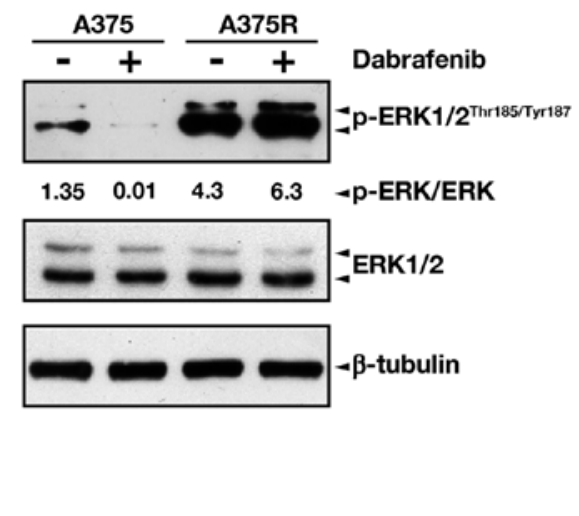

C

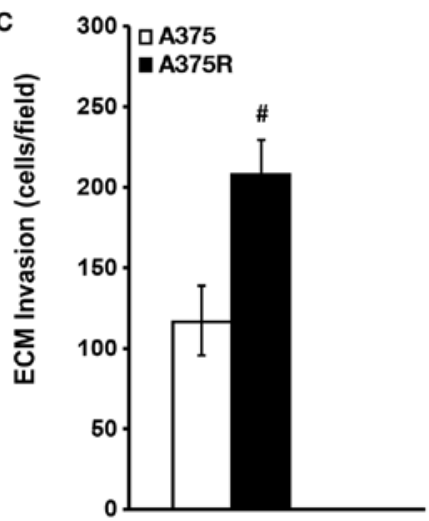

D

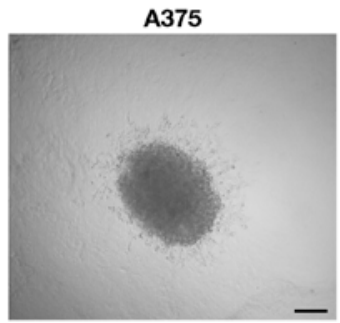

A375R

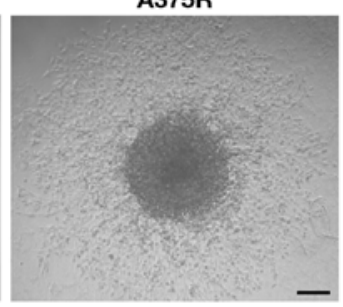

Figure 1. Characterization of the dabrafenib-resistant A375R cells. (A) A375 and A375R cells were incubated with increasing concentrations of dabrafenib or with DMSO alone for five days and then proliferation was assessed by the MTT assay. Data are expressed in terms of percentage of growth of cells treated with dabrafenib with respect to cells treated with DMSO alone (CTRL). Each value represents the arithmetic mean of six (A375) or three (A375R) independent experiments performed with triplicate samples. Bars, standard error of the mean (SEM). For each experiment, the dabrafenib $\mathrm{IC}_{50}$ value was calculated as described in Materials and methods. The $\mathrm{IC}_{50}$ mean value $\pm \mathrm{SEM}$ for A375 cells was $1.041 \pm 0.150 \mathrm{nM}$. The $\mathrm{IC}_{50}$ value for A375R was $>10 \mu \mathrm{M}$. (B) A375 and A375R cells were treated with $100 \mathrm{nM}$ dabrafenib or DMSO alone (-) for $6 \mathrm{~h}$. Equal amounts of total proteins were analyzed by immunoblotting using antibodies against pospho-ERK1/2 (Thr185/Tyr187) (p-ERK1/2), ERK1/2 and anti- $\beta$-tubulin. For each sample, the ratio between the densitometric level of phospho-ERK1/2 and ERK is shown. The results are representative of three independent experiments. (C) A375 and A375R cell ability to spontaneously invade the ECM was evaluated using Boyden chambers equipped with Matrigel-coated filter. Data are expressed as number of invading cells per microscopic field. Each value represents the arithmetic mean \pm SEM of three independent experiments. " $\mathrm{P}<0.05$ A375R vs. A375. (D) A375 and A375R spheroids were prepared and embedded into Matrigel as described in Materials and methods. After $48 \mathrm{~h}$ of culture, images depicting invasive outgrowth of spheroids were taken under a Leica inverted microscope at low magnification. Depicted spheroids are representative of three independent experiments. Scale bar represents $200 \mu \mathrm{m}$.

Recently, Liu et al (36) demonstrated that PLX4720 inhibited VEGF production in a melanoma cell line and xenografts, and that downregulation of VEGF expression occurred in the tumor of melanoma patients treated with PLX4720. Furthermore, Beazley-Long et al (37) reported that vemurafenib decreased VEGF-A expression in BRAF-mutant and drug-sensitive melanoma cells, whereas it increased this cytokine in BRAFwild-type melanoma cells. Therefore, to investigate the effects of dabrafenib on the metastatic potential of melanoma cells, A375 and A375R cells were treated with $100 \mathrm{nM}$ of the drug (or with DMSO as vehicle control) for $48 \mathrm{~h}$ and then analyzed for the ability to invade the ECM under basal conditions and in response to exogenously added VEGF-A, as well as for VEGF-A secretion and VEGFR-2 expression.

The results illustrated in Fig. 2A show that both cell lines responded to VEGF-A with an increase of ECM invasion, and that not only spontaneous but also VEGF-A-induced invasive capacity was higher in the A375R cell line as compared with the parental counterpart. Dabrafenib significantly inhibited spontaneous and VEGF-A-induced ECM invasion in A375 cells. In contrast, A375R cell invasiveness was markedly stimulated by the drug in both conditions.

VEGF-A secretion in the culture supernatants of A375 and A375R cells, and VEGFR-2 expression in the two cell lines were evaluated by specific ELISA and western blot analysis, respectively. We found that basal secretion of VEGF-A was higher in A375R cells as compared with parental A375 cells (Fig. 2B). Moreover, VEGF-A secretion was markedly impaired in dabrafenib-treated A375 cells, whereas it was significantly increased in drug-treated A375R cells. Exposure to dabrafenib caused a reduction of VEGFR-2 expression in A375 cells but it did not substantially affect the receptor levels in A375R cells (Fig. 2C). Of note, the effects of $1.5 \mu \mathrm{M}$ dabrafenib on A375R invasiveness, VEGF-A secretion and VEGFR-2 expression were comparable to those produced by $100 \mathrm{nM}$ of the drug (data not shown).

Bevacizumab inhibits dabrafenib-induced invasion in A375R cells. The findings that A375R cells were more invasive and secreted higher levels of VEGF-A than A375 cells, and 

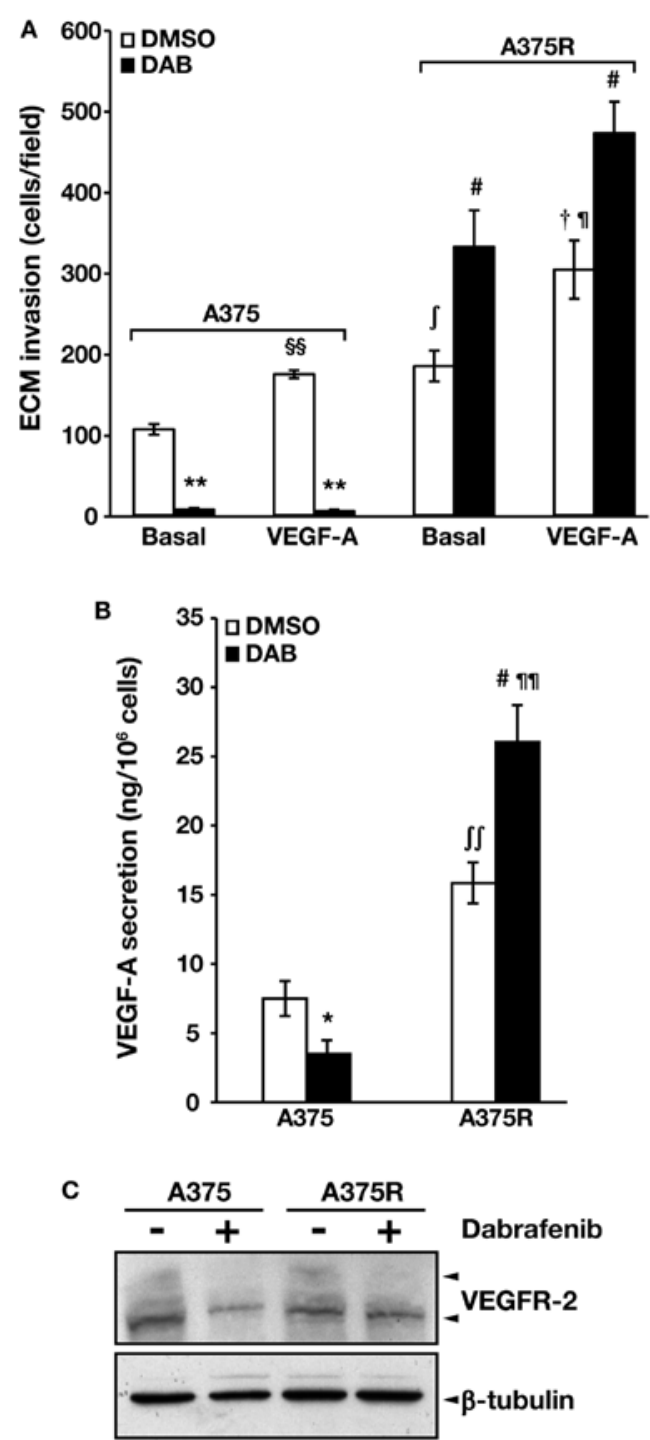

Figure 2. Dabrafenib inhibits ECM invasion and VEGF-A secretion in A375 cells whereas it enhances these functions in A375R cells. (A) The cells were cultured in the presence of $100 \mathrm{nM}$ dabrafenib (DAB) or DMSO alone for $48 \mathrm{~h}$. Thereafter, cell ability to invade the ECM, either spontaneously (Basal) or in response to VEGF-A ( $20 \mathrm{ng} / \mathrm{ml})$ was evaluated using Boyden chambers equipped with Matrigel-coated filter. Data are expressed as number of invading cells per microscopic field. Each value represents the arithmetic mean \pm SEM of three independent experiments. ${ }^{\S}{ }^{\S} \mathrm{P}<0.01$ A375/VEGF-A vs. A375/Basal; *** $\mathrm{P}<0.01$ A375/DAB vs. A375/DMSO; ${ }^{\dagger} \mathrm{P}<0.05$ A375R/VEGF-A vs. A375R/Basal; ${ }^{\#} \mathrm{P}<0.05 \mathrm{~A} 375 \mathrm{R} / \mathrm{DAB}$ vs. A375R/DMSO; ${ }^{\mathrm{P}}<0.05$ A375R/basal vs. A375/basal; ' $\mathrm{P}<0.05$ A375R/VEGF-A vs. A375/VEGF-A. (B) A375 and A375R cells were cultured with $100 \mathrm{nM}$ dabrafenib or DMSO alone for $48 \mathrm{~h}$. Culture supernatants were then collected and the amount of VEGF-A quantified using ELISA. Each value represents the arithmetic mean \pm SEM of four independent experiments. ${ }^{*} \mathrm{P}<0.05$ A375/DAB vs. A375/DMSO; ${ }^{\text {P }}<0.05$ A375R/DAB vs. A375R/DMSO ${ }^{\int 5} \mathrm{P}<0.01$ A375R/DMSO vs. A375/DMSO; ${ }^{95} \mathrm{P}<0.01 \mathrm{~A} 375 \mathrm{R} / \mathrm{DAB}$ vs. A375/DAB. (C) A375 and A375R cells were treated with $100 \mathrm{nM}$ dabrafenib or DMSO alone (-) for $48 \mathrm{~h}$. Equal amounts of total proteins were analyzed by immunoblotting using antibodies against VEGFR-2 or $\beta$-tubulin. The results are representative of two independent experiments.

responded to dabrafenib with a further increase of ECM invasion and VEGF-A secretion, prompted us to investigate whether inhibition of VEGF-A binding to its cognate RTKs could impair spontaneous and dabrafenib-induced invasiveness of A375R cells. To this end, the cells were treated with $100 \mathrm{nM}$ dabrafenib or DMSO alone for $48 \mathrm{~h}$, and then assayed

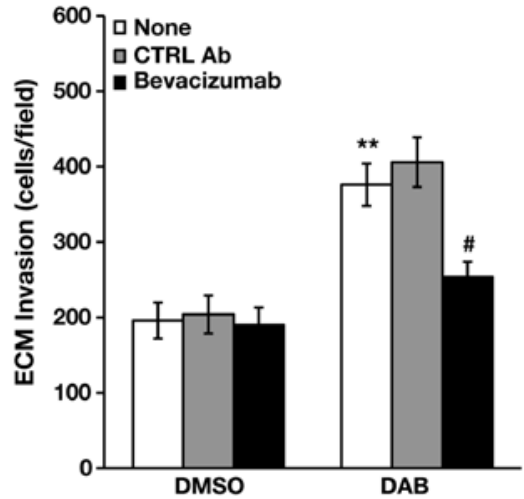

Figure 3. Bevacizumab inhibits dabrafenib-induced stimulation of A375R cell invasiveness. A375R cells were treated with $100 \mathrm{nM}$ dabrafenib (DAB) or DMSO alone for $48 \mathrm{~h}$ and then assayed for their ability to invade the ECM in the presence of the anti-VEGF-A monoclonal antibody bevacizumab $(5 \mu \mathrm{g} / \mathrm{ml})$ or a control antibody (CTRL Ab) or in the absence of antibodies (None). Data are expressed as number of invading cells per microscopic field. Each value represents the arithmetic mean \pm SEM of three independent experiments. ${ }^{* *} \mathrm{P}<0.01$ None/DAB vs. None/DMSO; ${ }^{\#} \mathrm{P}<0.05 \mathrm{DAB} /$ Bevacizumab vs. DAB/None and vs. DAB/CTRL Ab.

for ECM invasion in the absence or in the presence of the anti-VEGF-A monoclonal antibody bevacizumab $(38,39)$, or of a control antibody. As illustrated in Fig. 3, bevacizumab did not affect ECM invasion of DMSO-treated cells, whereas it abrogated dabrafenib-induced stimulation of A375R cell invasiveness.

AKT silencing prevents dabrafenib-induced stimulation of the invasive capacity of A375R cells. VEGF-A binding to VEGFR-2 can activate a number of downstream signaling pathways, including the MAPK/ERK and PI3K/AKT cascades $(40,41)$. Moreover, previous studies (42) demonstrated that VEGF-A overproduction and concomitant expression of its receptors promote melanoma cell growth and survival through the activation of the MAPK/ERK and PI3K/AKT signaling pathways. We therefore investigated whether, in addition to reactivation of the MAKP/ERK signaling in the presence of dabrafenib, A375R cells also showed hyperactivation of the PI3K/AKT pathway. Western blot analysis of total and phosphorylated AKT in A375 and A375R cells, showed that the drug-resistant subline expressed higher basal levels of phosphorylated AKT as compared with the parental cell line (Fig. 4A). Moreover, in both cell lines exposure to $100 \mathrm{nM}$ dabrafenib for $48 \mathrm{~h}$ enhanced the levels of phosphorylated AKT (Fig. 4A). Exome sequencing performed in A375 and A375R cells did not reveal mutations in the $A K T 1, A K T 3, P I K 3 C A, P I K 3 C G, P I K 3 R 2$ and PHLPP1 genes, or PTEN loss.

To establish whether hyperactivation of the PI3K/AKT pathway could underlie the increased invasive capacity of A375R cells, AKT1 was silenced in these cells using specific siRNAs. The results illustrated in Fig. 4B show that total AKT levels were efficiently reduced in the siAKT-transfected cells exposed to DMSO or to $100 \mathrm{nM}$ dabrafenib for $48 \mathrm{~h}$. Notably, DMSO-treated and dabrafenib-treated siAKT-transfected cells also showed a marked reduction of phospho-AKT levels. This finding indicates that in A375R cells, basal and dabrafenibinduced phosphorylation of AKT mainly involve the AKT1 isoform. As observed for bevacizumab, AKT1 silencing 


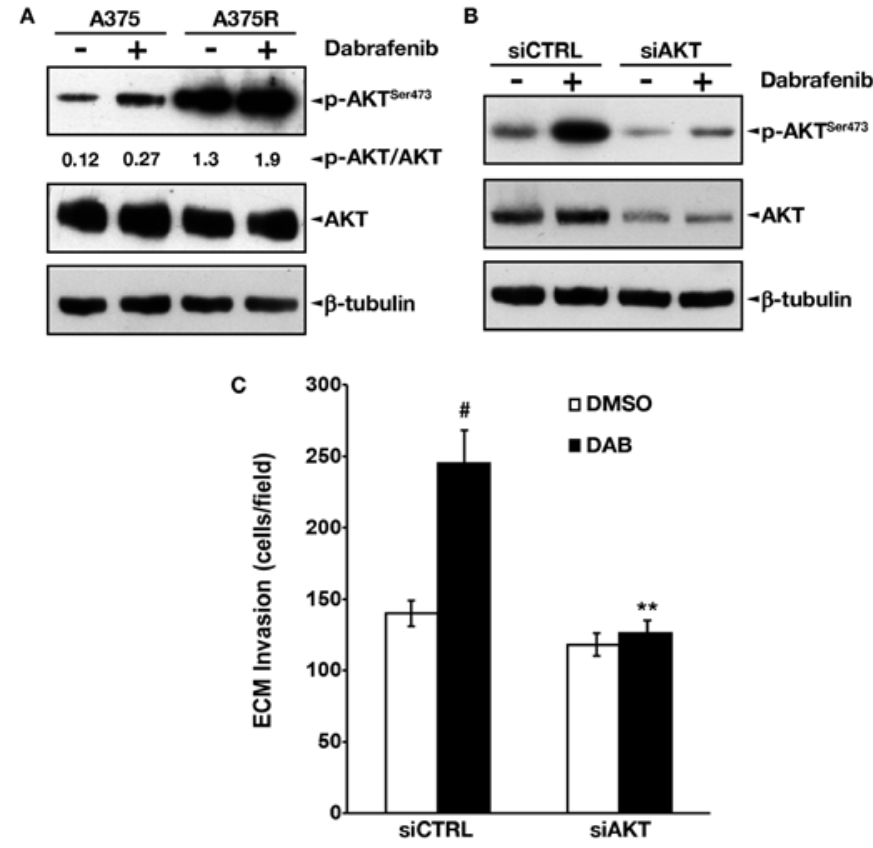

Figure 4. AKT silencing inhibits dabrafenib-induced stimulation of A375R invasiveness. (A) A375 and A375R cells were treated with $100 \mathrm{nM}$ dabrafenib or DMSO alone (-) for $48 \mathrm{~h}$. Equal amounts of total proteins were analyzed by immunoblotting using antibodies against phospho-AKT (Ser473) (p-AKT), AKT or $\beta$-tubulin. For each sample, the ratio between the densitometric level of phospho-AKT and AKT is shown. The results are representative of three independent experiments. (B) A375R cells were transiently transfected with $10 \mathrm{nM}$ of siAKT or siCTRL and $24 \mathrm{~h}$ later incubated with $100 \mathrm{nM}$ dabrafenib or DMSO alone (-). After $48 \mathrm{~h}$ of culture, equal amounts of total proteins were analyzed by immunoblotting using antibodies against phospho-AKT (Ser473) (p-AKT), AKT or $\beta$-tubulin. The results are representative of two independent experiments. (C) A375R cells were transfected and treated as described in (B) and then assayed for spontaneous invasion of ECM. Data are expressed as number of invading cells per microscopic field. Each value represents the arithmetic mean \pm SEM of three independent experiments. ${ }^{\#} \mathrm{P}<0.05$ siCTRL/DAB vs. siCTRL/DMSO; ${ }^{* *} \mathrm{P}<0.01$ siAKT/DAB vs. SiCTRL/DAB

failed to reduce basal invasiveness of A375R cells, whereas it completely abrogated upregulation of ECM invasion induced by dabrafenib (Fig. 4C).

The PI3K/mTOR inhibitor GSK2126458A impairs invasiveness and VEGF-A secretion induced by dabrafenib in A375R cells. Based on the key role played by MAPK/ERK signaling reactivation and $\mathrm{PI} 3 \mathrm{~K} / \mathrm{AKT} / \mathrm{mTOR}$ signaling upregulation in acquired resistance to BRAFi, several therapeutic approaches co-targeting the MAPK/ERK and the PI3K/AKT/mTOR pathways in patients with BRAF-mutant melanoma are underway to improve the efficacy and durability of clinical response (12; https://www.clinicaltrials.gov/).

We therefore investigated whether co-treatment of A375R cells with the dual PI3K/mTOR inhibitor GSK2126458A could antagonize the stimulating effects exerted by dabrafenib on ECM invasion and VEGF-A secretion. Preliminary experiments were also performed to evaluate A375R cell sensitivity to the growth inhibitory effect of GSK2126458A and to select the drug concentration to be used in combination with dabrafenib.

In agreement with previous findings (43), MTT proliferation assays, performed after five days of cell exposure to
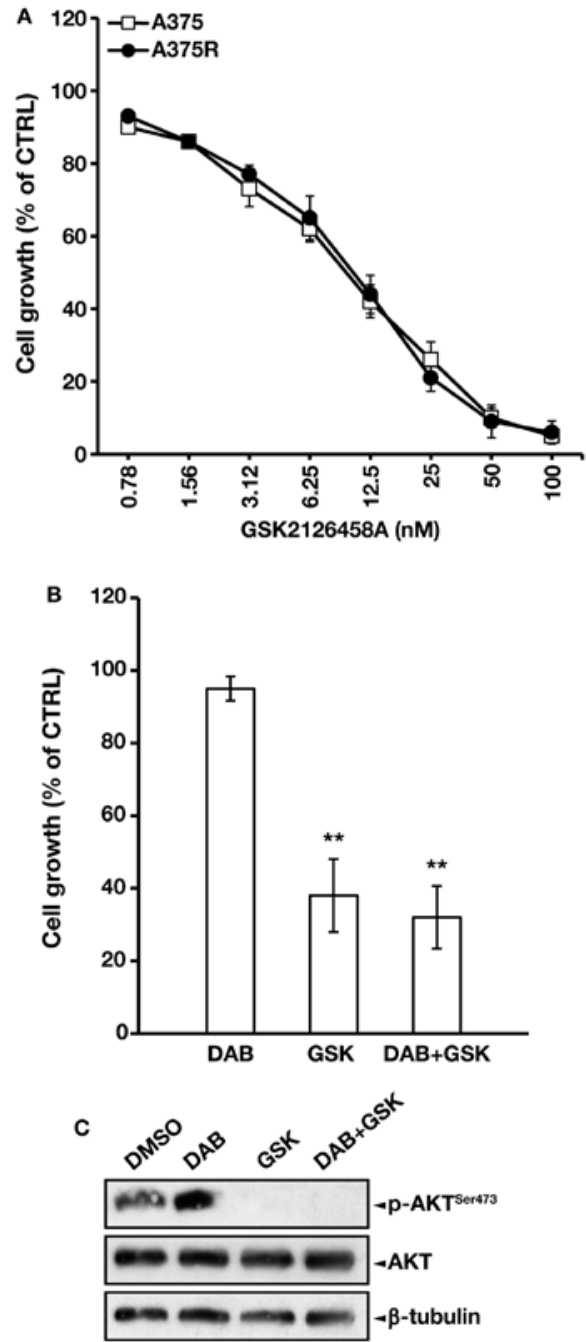

Figure 5. GSK2126458A alone or in combination with dabrafenib inhibits proliferation and AKT phosphorylation in A375R cells. (A) A375 and A375R cells were incubated with increasing concentrations of GSK2126458A or with DMSO alone for five days and then proliferation was assessed by the MTT assay. Data are expressed in terms of percentage of growth of cells treated with GSK2126458A with respect to cells treated with DMSO alone (CTRL). Each value represents the arithmetic mean of three independent experiments performed with triplicate samples. Bars, SEM. GSK2126458A IC I0 $_{\text {mean }}$ value \pm SEM was $7.836 \pm 0.597 \mathrm{nM}$ for A375 cells and $8.940 \pm 1.654 \mathrm{nM}$ for A375R cells. The difference between the $\mathrm{IC}_{50}$ values was not statistically significant. (B) A375R cells were cultured with DMSO alone, $100 \mathrm{nM}$ dabrafenib (DAB), $20 \mathrm{nM}$ GSK2126458A (GSK) or a combination of the two drugs for five days and then assayed for proliferation using the MTT assay. Data are expressed in terms of percentage of growth of drug-treated cells with respect to DMSO-treated cells (CTRL). Each value represents the arithmetic mean \pm SEM of three independent experiments performed with triplicate samples. Bars, SEM. ${ }^{* *}$ P $<0.01$ GSK and DAB+GSK vs. DAB. (C) A375R cells were cultured with DMSO alone, $100 \mathrm{nM}$ dabrafenib (DAB), $20 \mathrm{nM}$ GSK2126458A (GSK) or a combination of the two drugs for $48 \mathrm{~h}$. Equal amounts of total proteins were analyzed by immunoblotting using antibodies against phospho-AKT (Ser473) (p-AKT), AKT or $\beta$-tubulin. The results are representative of two independent experiments

graded concentrations of GSK2126458A, revealed that the dabrafenib-resistant subline was responsive to the PI3K/mTOR inhibitor, displaying a drug $\mathrm{IC}_{50}$ value comparable to that of the parental cells (Fig. 5A).

The clinically achievable concentration of $20 \mathrm{nM}$ GSK2126458A was then selected for the subsequent experiments. This drug concentration inhibited A375R proliferation 

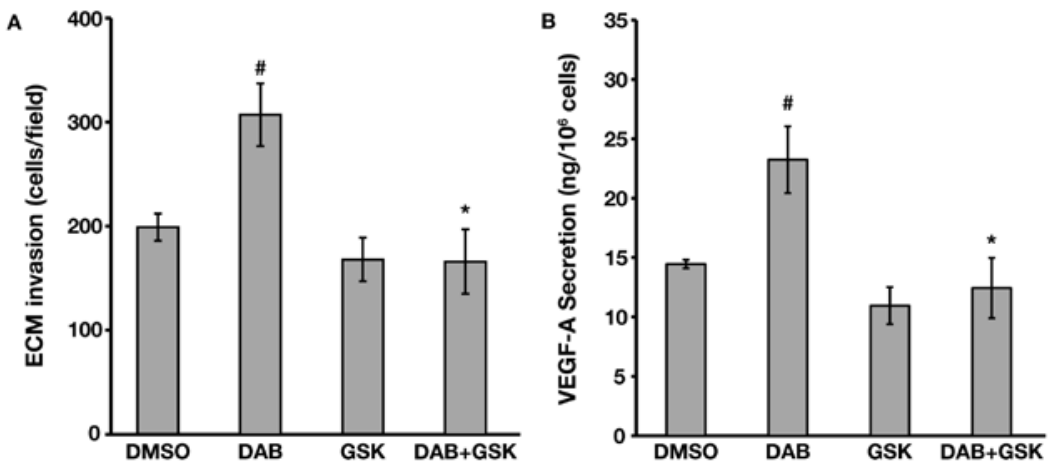

Figure 6. GSK2126458A abrogates dabrafenib-induced stimulation of ECM invasion and VEGF-A secretion in A375R cells. (A) The cells were cultured with DMSO, $100 \mathrm{nM}$ dabrafenib (DAB), $20 \mathrm{nM}$ GSK2126458A (GSK) or a combination of the two drugs for $48 \mathrm{~h}$ and then assayed for their ability to spontaneously invade the ECM. Data are expressed as number of invading cells per microscopic field. Each value represents the arithmetic mean \pm SEM of three independent experiments. " $\mathrm{P}<0.05$ DAB vs. DMSO; ${ }^{*} \mathrm{P}<0.05 \mathrm{DAB}+\mathrm{GSK}$ vs. DAB. (B) A375R cells were treated as described in (A). Culture supernatants were then collected and the amount of VEGF-A quantified using ELISA. Each value represents the arithmetic mean $\pm \mathrm{SEM}$ of four independent experiments. ${ }^{*} \mathrm{P}<0.05 \mathrm{DAB}$ vs. DMSO; ${ }^{\mathrm{P}}<0.05 \mathrm{DAB}+\mathrm{GSK}$ vs. DAB.

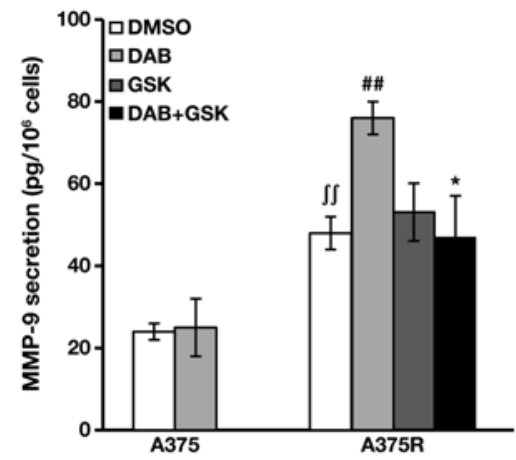

Figure 7. GSK2126458A abrogates dabrafenib-induced stimulation of MMP-9 secretion in A375R cells. A375 cells were cultured with DMSO alone or $100 \mathrm{nM}$ dabrafenib (DAB), whereas A375R were cultured with DMSO alone, $100 \mathrm{nM}$ dabrafenib, $20 \mathrm{nM}$ GSK2126458A (GSK) or a combination of the two drugs. After $48 \mathrm{~h}$ of drug exposure, culture supernatants were collected and the amount of MMP-9 determined by ELISA. Each value represents the arithmetic mean \pm SEM of four independent experiments. ${ }^{\# \#} \mathrm{P}<0.01 \mathrm{~A} 375 \mathrm{R} / \mathrm{DAB}$ vs. A375R/DMSO; $\mathrm{P}<0.05 \mathrm{~A} 375 \mathrm{R} / \mathrm{DAB}+\mathrm{GSK}$ vs. A375R/DAB; ${ }^{\int J} \mathrm{P}<0.01 \mathrm{~A} 375 \mathrm{R} / \mathrm{DMSO}$ vs. A375/DMSO.

by $\sim 70 \%$, either alone or in combination with dabrafenib (Fig. 5B). Moreover, a 48 h-exposure to 20 nM GSK2126458A completely abrogated AKT phosphorylation in both DMSOtreated and dabrafenib-treated A375R cells (Fig. 5C) without affecting cell viability (data not shown).

A375R cells were exposed to DMSO, 20 nM GSK2126458A, $100 \mathrm{nM}$ dabrafenib or a combination of the two drugs for $48 \mathrm{~h}$ and then tested for ECM invasion and VEGF-A secretion. Invasiveness of A375R cells was not substantially affected by GSK2126458A alone (Fig. 6A). However, the PI3K/mTOR inhibitor abrogated dabrafenib-induced stimulation of ECM invasion (Fig. 6A). In agreement with the invasion assays, VEGF-A secretion was not significantly altered in A375R exposed to GSK2126458A alone (Fig. 6B). On the other hand, the $\mathrm{PI} 3 \mathrm{~K} / \mathrm{mTOR}$ inhibitor was able to completely counteract the upregulation of VEGF-A release caused by the BRAFi (Fig. 6B).

The PI3K/mTOR inhibitor GSK2126458A impairs MMP-9 secretion induced by dabrafenib in A375R cells. MMPs, a large family of proteolytic enzymes able to degrade the ECM, play a critical role in many physiological processes and are also implicated in tumor angiogenesis and metastatic spreading of cancer cells (reviewed in refs. 44,45). In melanoma, increased expression of MMP-1, MMP-2 and MMP-9 has been associated with an invasive phenotype (46). Moreover, VEGF-A has been reported to upregulate the expression of certain MMPs, including MMP-9, in endothelial cells and ovarian cancer cells $(47,48)$.

We, therefore, determined MMP-9 levels in culture supernatants of A375 and A375R cells, treated with DMSO or $100 \mathrm{nM}$ dabrafenib for $48 \mathrm{~h}$. In A375R cells, MMP-9 secretion was also evaluated after treatment with 20 nM GSK2126458A, alone or in combination with dabrafenib.

The results illustrated in Fig. 7 show that A375 cells secreted low amounts of MMP-9, which were not affected by dabrafenib treatment. A375R displayed levels of MMP-9 secretion 2-fold higher than those detected in A375 cells. Moreover, in the resistant subline the release of MMP-9 was significantly stimulated by dabrafenib. Similarly to the results obtained with VEGF-A, GSK2126458A alone did not alter basal MMP-9 secretion in A375R cells, but abrogated the upregulation caused by dabrafenib treatment (Fig. 7).

\section{Discussion}

In the present study we describe for the first time the effects of dabrafenib on the invasive capacity of BRAF-mutant melanoma cells sensitive or with acquired resistance to the antiproliferative activity of this BRAFi, as well as the modulating effect of GSK2126458A, a dual PI3K/mTOR inhibitor, on the responses of the resistant cells to dabrafenib.

The invasive behavior of melanoma cells with acquired resistance to dabrafenib, the only BRAFi presently approved for melanoma therapy beside vemurafenib, has not been investigated so far. However, increased invasiveness of melanoma cells with secondary resistance to the BRAFi PLX4720 $(18,22)$, SB590885 (20), or vemurafenib (21) has been previously reported and linked to hyperactivation of the SRC family kinase-STAT3 signaling pathway $(18,20)$, upregulation of several gene products involved in the metastatic process (21), 
or increased expression of IL-8 (22). Our results showing that the dabrafenib-resistant cell line A375R displayed higher invasive capacity and higher production of VEGF-A and MMP-9 as compared with the drug-sensitive parental cell line A375 are consistent with these previous findings and provide further insight into melanoma biological characteristics associated with acquired resistance to BRAFi. Notably, in A375 cells exposure to dabrafenib impaired invasiveness, VEGFR-2 expression and VEGF-A secretion, and did not affect MMP-9 release. In contrast, in A375R cells treatment with dabrafenib caused an increase of the invasive capacity, as well as of VEGF-A and MMP-9 release, and did not substantially alter VEGFR-2 expression. These data point out that cells with acquired resistance to dabrafenib, not only are more invasive than the sensitive parental cells, but also respond to the drug with a further increase of their metastatic potential.

In the present study, we focused our investigation on the possible mechanisms underlying the effects of dabrafenib on the invasive capacity of the resistant cells, and on the possibility to modulate those effects. Indeed, there are some contrasting data regarding the clinical outcome that could be achieved by continuing BRAFi monotherapy in patients who had developed secondary resistance. Carlino et al (49) showed that melanoma cells with in vitro or in vivo acquired resistance to dabrafenib still responded to the BRAFi with reduced proliferation, even though they did not undergo apoptosis. These authors also reported a rapid acceleration of the disease upon dabrafenib suspension in a melanoma patient who had been treated with the drug for about six additional months after progression. Accordingly, clinical benefit of continuing BRAFi beyond RECIST disease progression was demonstrated in a large group of melanoma patients by Chan et al (50). In contrast, a preclinical study conducted with two different primary human melanoma xenograft models demonstrated that tumors with acquired resistance to vemurafenib were dependent on this drug for continuous proliferation, and that withdrawal of vemurafenib caused regression of established drug-resistant tumors (51). Furthermore, Hartsough et al (52) showed that melanoma cells with acquired resistance to PLX4720 due to the expression of mutant BRAF splice variants grow more efficiently, both in vitro and in vivo, in the presence of PLX4720 than in the absence of the inhibitor. Although randomized prospective trials are necessary to establish the role that prolonged BRAF inhibition may have in patients undergoing disease progression, the findings that dabrafenib stimulated ECM invasion and VEGF-A and MMP-9 production in A375R cells, cast, at least, a note of caution for the continuation of BRAFi monotherapy beyond progression. In vivo release of VEGF-A by melanoma cells can promote tumor growth and metastasis by both paracrine and autocrine mechanisms, namely supporting angiogenesis and stimulating melanoma cell proliferation, migration and invasion (35,40-42). Accordingly, elevated expression of VEGF-A and its receptors has been associated with melanoma progression (53). Moreover, MMP-9 is an important regulator of tumor angiogenesis and vasculogenesis, and has also been implicated in the formation of the metastatic niche (44). Although continuing single agent dabrafenib beyond progression could suppress the growth of those cells that within a heterogeneous tumor cell population have remained sensitive to the drug, it might accelerate the metastatic spreading of the drug-resistant cells. A better clinical benefit might be achieved by combining dabrafenib with a drug able to counteract the stimulating effects of the BRAFi on melanoma cell invasiveness.

In the present study, we show that dabrafenib-induced stimulation of A375R invasive capacity was markedly inhibited in the presence of bevacizumab, a therapeutic anti-VEGF-A mAb which prevents the interaction of the angiogenic factor with its receptors VEGFR-1 and VEGFR-2 $(38,39)$. This finding supports the hypothesis that dabrafenib-induced stimulation of ECM invasion in A375R cells mainly relies on drug-mediated upregulation of VEGF-A secretion and the subsequent engagement of signaling pathways regulating melanoma cell invasiveness. In this regard, the PI3K/AKT/mTOR signaling cascade, which is one of the signaling pathways activated upon binding of VEGF-A to VEGFR-1 and VEGFR-2 (40), appears to play a crucial role. Indeed, AKT1 silencing by specific siRNAs abrogated the stimulating effect of dabrafenib on A375R cell invasive capacity. Moreover, when A375R cells were treated with dabrafenib in combination with GSK2126458A, phosphorylation of AKT was entirely suppressed and this molecular event was accompanied by abrogation of dabrafenib-induced stimulation of ECM invasion and of VEGF-A and MMP-9 production. Several studies have demonstrated that co-targeting the PI3K/AKT/mTOR is an effective strategy to reverse acquired resistance to the growth suppressive effects of BRAFi (43,54-58). Our data, showing that A375R cells were highly responsive to GSK2126458A, as a single agent or in combination with dabrafenib, are consistent with those studies, and show that inhibition of the PI3K/AKT/ mTOR pathway can also efficiently counteract dabrafenibinduced stimulation of the invasive capacity of melanoma cells with required resistance to this agent. Of note, neither bevacizumab, nor anti-AKT1 siRNA were able to impair basal invasiveness of A375R. Moreover, GSK2126458A alone, at the concentration selected for the combination with dabrafenib, did not alter basal ECM invasion and VEGF-A and MMP-9 secretion in A375R cells even if efficiently impaired AKT phosphorylation. Taken together, these data suggest that the higher basal invasive capacity displayed by A375R cells does not depend on VEGF-A engagement of its cognate RTKs or on AKT hyperactivation observed in these cells. It is possible that one or more mechanisms previously described to be involved in the increased aggressiveness of melanoma cells resistant to other BRAFi also underlie the elevated invasive behavior of the dabrafenib-resistant cell line generated in the present study. However, further investigations are required to address this issue.

In conclusion, our results demonstrate that dabrafenib effectively impairs the metastatic potential of BRAF-mutant melanoma cells sensitive to the antiproliferative activity of the drug. They also provide evidence that melanoma cells with acquired resistance to dabrafenib possess a more invasive phenotype which is further stimulated by exposure to the inhibitor via upregulation of VEGF-A secretion and activation of the PI3K/AKT/mTOR signaling pathway. Our data suggest that in patients progressing on dabrafenib therapy, a regimen combining the BRAFi with bevacizumab or with an inhibitor of the PI3K/AKT/mTOR pathway might provide a clinical benefit higher than that of extended BRAFi monotherapy. Notably, the 
combination of vemurafenib and cobimetinib (MEK inhibitor) with or without bevacizumab is being testing in a randomized phase 2 clinical trial in patients with unresectable or metastatic BRAF-mutant melanoma (NCT01495988; https://www. clinicaltrials.gov/). A phase II clinical study is also ongoing to assess the efficacy and safety of the combination of LGX818 (BRAFi) with the PI3K inhibitor BKM120, or other targeted agents, in patients with unresectable or metastatic BRAFmutant melanoma after relapse on LGX818 (NCT01820364; https://www.clinicaltrials.gov/).

\section{Acknowledgements}

The present study was supported by the Italian Association for Cancer Research (AIRC, Investigator Grant Project 17585) and by the Italian Ministry of Health (Grant 5PerMille-2010). The authors thank GlaxoSmithKline for the supply of dabrafenib and GSK2126458A, Maurizio Inzillo (Office of External Relations and Communication, IDI-IRCCS) for the artwork and Laura Bonmassar (Laboratory of Molecular Oncology, IDI-IRCCS) for technical help. The authors wish also to thank Professor Maria Marino (Department of Science, Biomedical Sciences and Technology Section, University 'Roma Tre', Rome, Italy) for helpful discussion.

\section{References}

1. Davies H, Bignell GR, Cox C, Stephens P, Edkins S, Clegg S, Teague J, Woffendin H, Garnett MJ, Bottomley W, et al: Mutations of the BRAF gene in human cancer. Nature 417: 949-954, 2002.

2. Lopez-Bergami P: The role of mitogen- and stress-activated protein kinase pathways in melanoma. Pigment Cell Melanoma Res 24: 902-921, 2011.

3. Sullivan RJ and Flaherty K: MAP kinase signaling and inhibition in melanoma. Oncogene 32: 2373-2379, 2013.

4. Chapman PB, Hauschild A, Robert C, Haanen JB, Ascierto P, Larkin J, Dummer R, Garbe C, Testori A, Maio M, et al; BRIM-3 Study Group: Improved survival with vemurafenib in melanoma with BRAF V600E mutation. N Engl J Med 364: 2507-2516, 2011.

5. Flaherty KT, Robert C, Hersey P, Nathan P, Garbe C, Milhem M, Demidov LV, Hassel JC, Rutkowski P, Mohr P, et al; METRIC Study Group: Improved survival with MEK inhibition in BRAFmutated melanoma. N Engl J Med 367: 107-114, 2012.

6. Hauschild A, Grob JJ, Demidov LV, Jouary T, Gutzmer R, Millward M, Rutkowski P, Blank CU, Miller WH Jr, Kaempgen E, et al: Dabrafenib in BRAF-mutated metastatic melanoma: A multicentre, open-label, phase 3 randomised controlled trial Lancet 380: 358-365, 2012

7. Flaherty KT, Infante JR, Daud A, Gonzalez R, Kefford RF, Sosman J, Hamid O, Schuchter L, Cebon J, Ibrahim N, et al: Combined BRAF and MEK inhibition in melanoma with BRAF V600 mutations. N Engl J Med 367: 1694-1703, 2012.

8. Robert C, Karaszewska B, Schachter J, Rutkowski P, Mackiewicz A, Stroiakovski D, Lichinitser M, Dummer R, Grange F, Mortier L, et al: Improved overall survival in melanoma with combined dabrafenib and trametinib. N Engl J Med 372: 30-39, 2015

9. Long GV, Stroyakovskiy D, Gogas H, Levchenko E, de Braud F, Larkin J, Garbe C, Jouary T, Hauschild A, Grob JJ, et al: Dabrafenib and trametinib versus dabrafenib and placebo for Val600 BRAF-mutant melanoma: A multicentre, double-blind, phase 3 randomised controlled trial. Lancet 386: 444-451, 2015.

10. Sullivan RJ and Flaherty KT: Resistance to BRAF-targeted therapy in melanoma. Eur J Cancer 49: 1297-1304, 2013.

11. Holderfield M, Deuker MM, McCormick F and McMahon M: Targeting RAF kinases for cancer therapy: BRAF-mutated melanoma and beyond. Nat Rev Cancer 14: 455-467, 2014.

12. Fedorenko IV, Gibney GT, Sondak VK and Smalley KSM: Beyond BRAF: Where next for melanoma therapy? Br J Cancer 112: 217-226, 2015.
13. Spagnolo F, Ghiorzo P, Orgiano L, Pastorino L, Picasso V, Tornari E, Ottaviano V and Queirolo P: BRAF-mutant melanoma: Treatment approaches, resistance mechanisms, and diagnostic strategies. Onco Targets Ther 8: 157-168, 2015.

14. Yadav V, Zhang X, Liu J, Estrem S, Li S, Gong XQ, Buchanan S, Henry JR, Starling JJ and Peng SB: Reactivation of mitogenactivated protein kinase (MAPK) pathway by FGF receptor 3 (FGFR3)/Ras mediates resistance to vemurafenib in human B-RAF V600E mutant melanoma. J Biol Chem 287: 28087-28098, 2012.

15. Sabbatino F, Wang Y, Wang X, Flaherty KT, Yu L, Pepin D, Scognamiglio G, Pepe S, Kirkwood JM, Cooper ZA, et al: PDGFR $\alpha$ up-regulation mediated by sonic hedgehog pathway activation leads to BRAF inhibitor resistance in melanoma cells with BRAF mutation. Oncotarget 5: 1926-1941, 2014.

16. Wang J, Huang SK, Marzese DM, Hsu SC, Kawas NP, Chong KK, Long GV, Menzies AM, Scolyer RA, Izraely S, et al: Epigenetic changes of EGFR have an important role in BRAF inhibitorresistant cutaneous melanomas. J Invest Dermatol 135: 532-541, 2015.

17. Halaban R, Zhang W, Bacchiocchi A, Cheng E, Parisi F, Ariyan S, Krauthammer M, McCusker JP, Kluger Y and Sznol M: PLX4032, a selective BRAF ${ }^{\mathrm{V} 600 \mathrm{E}}$ kinase inhibitor, activates the ERK pathway and enhances cell migration and proliferation of BRAF melanoma cells. Pigment Cell Melanoma Res 23: 190-200, 2010.

18. Girotti MR, Pedersen M, Sanchez-Laorden B, Viros A, Turajlic S, Niculescu-Duvaz D, Zambon A, Sinclair J, Hayes A, Gore M, et al: Inhibiting EGF receptor or SRC family kinase signaling overcomes BRAF inhibitor resistance in melanoma. Cancer Discov 3: 158-167, 2013

19. Tsai J, Lee JT, Wang W, Zhang J, Cho H, Mamo S, Bremer R, Gillette S, Kong J, Haass NK, et al: Discovery of a selective inhibitor of oncogenic B-Raf kinase with potent antimelanoma activity. Proc Natl Acad Sci USA 105: 3041-3046, 2008.

20. Vultur A, Villanueva J, Krepler C, Rajan G, Chen Q, Xiao M, Li L, Gimotty PA, Wilson M, Hayden J, et al: MEK inhibition affects STAT3 signaling and invasion in human melanoma cell lines. Oncogene 33: 1850-1861, 2014.

21. Zubrilov I, Sagi-Assif O, Izraely S, Meshel T, Ben-Menahem S, Ginat R, Pasmanik-Chor M, Nahmias C, Couraud PO, Hoon DSB, et al: Vemurafenib resistance selects for highly malignant brain and lung-metastasizing melanoma cells. Cancer Lett 361: 86-96, 2015.

22. Sanchez-Laorden B, Viros A, Girotti MR, Pedersen M, Saturno G, Zambon A, Niculescu-Duvaz D, Turajlic S, Hayes A, Gore M, et al: BRAF inhibitors induce metastasis in RAS mutant or inhibitor-resistant melanoma cells by reactivating MEK and ERK signaling. Sci Signal 7: ra30, 2014.

23. Vergani E, Vallacchi V, Frigerio S, Deho P, Mondellini P, Perego P, Cassinelli G, Lanzi C, Testi MA, Rivoltini L, et al: Identification of MET and SRC activation in melanoma cell lines showing primary resistance to PLX4032. Neoplasia 13: 1132-1142, 2011.

24. Li H and Durbin R: Fast and accurate short read alignment with Burrows-Wheeler transform. Bioinformatics 25: 1754-1760, 2009.

25. McKenna A, Hanna M, Banks E, Sivachenko A, Cibulskis K, Kernytsky A, Garimella K, Altshuler D, Gabriel S, Daly M, et al: The Genome Analysis Toolkit: A MapReduce framework for analyzing next-generation DNA sequencing data. Genome Res 20: 1297-1303, 2010

26. Yang $\mathrm{H}$ and Wang $\mathrm{K}$ : Genomic variant annotation and prioritization with ANNOVAR and wANNOVAR. Nat Protoc 10: 1556-1566, 2015.

27. Pepponi R, Marra G, Fuggetta MP, Falcinelli S, Pagani E, Bonmassar E, Jiricny J and D'Atri S: The effect of $O^{6}$-alkylguanine-DNA alkyltransferase and mismatch repair activities on the sensitivity of human melanoma cells to temozolomide, 1,3-bis(2-chloroethyl)1-nitrosourea, and cisplatin. J Pharmacol Exp Ther 304: 661-668, 2003.

28. Caporali S, Falcinelli S, Starace G, Russo MT, Bonmassar E, Jiricny J and D'Atri S: DNA damage induced by temozolomide signals to both ATM and ATR: Role of the mismatch repair system. Mol Pharmacol 66: 478-491, 2004.

29. Ruffini F, D'Atri S and Lacal PM: Neuropilin-1 expression promotes invasiveness of melanoma cells through vascular endothelial growth factor receptor-2-dependent and -independent mechanisms. Int J Oncol 43: 297-306, 2013. 
30. Naber HP, Wiercinska E, Ten Dijke P and van Laar T: Spheroid assay to measure TGF- $\beta$-induced invasion. J Vis Exp 57: e3337, 2011.

31. Merz C, Strecker A, Sykora J, Hill O, Fricke H, Angel P, Gieffers $\mathrm{C}$ and Peterziel $\mathrm{H}$ : Neutralization of the CD95 ligand by APG101 inhibits invasion of glioma cells in vitro. Anticancer Drugs 26: 716-727, 2015.

32. Lacal PM, Failla CM, Pagani E, Odorisio T, Schietroma C, Falcinelli S, Zambruno G and D'Atri S: Human melanoma cells secrete and respond to placenta growth factor and vascular endothelial growth factor. J Invest Dermatol 115: 1000-1007, 2000.

33. Falchook GS, Long GV, Kurzrock R, Kim KB, Arkenau HT Brown MP, Hamid O, Infante JR, Millward M, Pavlick A, et al: Dose selection, pharmacokinetics, and pharmacodynamics of BRAF inhibitor dabrafenib (GSK2118436). Clin Cancer Res 20 4449-4458, 2014.

34. Smalley KS, Lioni M and Herlyn M: Life isn't flat: Taking cancer biology to the next dimension. In Vitro Cell Dev Biol Anim 42: 242-247, 2006

35. Lacal PM, Ruffini F, Pagani E and D'Atri S: An autocrine loop directed by the vascular endothelial growth factor promotes invasiveness of human melanoma cells. Int J Oncol 27: 1625-1632, 2005.

36. Liu C, Peng W, Xu C, Lou Y, Zhang M, Wargo JA, Chen JQ, Li HS, Watowich SS, Yang Y, et al: BRAF inhibition increases tumor infiltration by $\mathrm{T}$ cells and enhances the antitumor activity of adoptive immunotherapy in mice. Clin Cancer Res 19: 393-403, 2013

37. Beazley-Long N, Gaston K, Harper SJ, Orlando A and Bates DO: Novel mechanisms of resistance to vemurafenib in melanoma V600E B-Raf reversion and switching VEGF-A splice isoform expression. Am J Cancer Res 5: 433-441, 2014.

38. Ferrara N, Hillan KJ, Gerber HP and Novotny W: Discovery and development of bevacizumab, an anti-VEGF antibody for treating cancer. Nat Rev Drug Discov 3: 391-400, 2004.

39. Keating GM: Bevacizumab: A review of its use in advanced cancer. Drugs 74: 1891-1925, 2014.

40. Koch S, Tugues S, Li X, Gualandi L and Claesson-Welsh L: Signal transduction by vascular endothelial growth factor receptors. Biochem J 437: 169-183, 2011.

41. Goel HL and Mercurio AM: VEGF targets the tumour cell. Nat Rev Cancer 13: 871-882, 2013.

42. Graells J, Vinyals A, Figueras A, Llorens A, Moreno A, Marcoval J, Gonzalez FJ and Fabra A: Overproduction of VEGF concomitantly expressed with its receptors promotes growth and survival of melanoma cells through MAPK and PI3K signaling. J Invest Dermatol 123: 1151-1161, 2004.

43. Greger JG, Eastman SD, Zhang V, Bleam MR, Hughes AM, Smitheman KN, Dickerson SH, Laquerre SG, Liu L and Gilmer TM: Combinations of BRAF, MEK, and PI3K/mTOR inhibitors overcome acquired resistance to the BRAF inhibitor GSK2118436 dabrafenib, mediated by NRAS or MEK mutations. Mol Cancer Ther 11: 909-920, 2012

44. Kessenbrock K, Plaks V and Werb Z: Matrix metalloproteinases: Regulators of the tumor microenvironment. Cell 141: 52-67, 2010.

45. Gialeli C, Theocharis AD and Karamanos NK: Roles of matrix metalloproteinases in cancer progression and their pharmacological targeting. FEBS J 278: 16-27, 2011.
46. Orgaz JL and Sanz-Moreno V: Emerging molecular targets in melanoma invasion and metastasis. Pigment Cell Melanoma Res 26: 39-57, 2013.

47. Ghosh S, Basu M and Roy SS: ETS-1 protein regulates vascular endothelial growth factor-induced matrix metalloproteinase- 9 and matrix metalloproteinase-13 expression in human ovarian carcinoma cell line SKOV-3. J Biol Chem 287: 15001-15015, 2012.

48. Claesson-Welsh L and Welsh M: VEGFA and tumour angiogenesis. J Intern Med 273: 114-127, 2013.

49. Carlino MS, Gowrishankar K, Saunders CAB, Pupo GM, Snoyman S, Zhang XD, Saw R, Becker TM, Kefford RF, Long GV, et al: Antiproliferative effects of continued mitogenactivated protein kinase pathway inhibition following acquired resistance to BRAF and/or MEK inhibition in melanoma. Mol Cancer Ther 12: 1332-1342, 2013.

50. Chan MMK, Haydu LE, Menzies AM, Azer MWF, Klein O, Lyle M, Clements A, Guminski A, Kefford RF and Long GV: The nature and management of metastatic melanoma after progression on BRAF inhibitors: Effects of extended BRAF inhibition. Cancer 120: 3142-3153, 2014.

51. Das Thakur M, Salangsang F, Landman AS, Sellers WR, Pryer NK, Levesque MP, Dummer R, McMahon M and Stuart DD: Modelling vemurafenib resistance in melanoma reveals a strategy to forestall drug resistance. Nature 494: 251-255, 2013.

52. Hartsough EJ, Basile KJ and Aplin AE: Beneficial effects of RAF inhibitor in mutant BRAF splice variant-expressing melanoma. Mol Cancer Res 12: 795-802, 2014.

53. Mehnert JM, McCarthy MM, Jilaveanu L, Flaherty KT, Aziz S, Camp RL, Rimm DL and Kluger HM: Quantitative expression of VEGF, VEGF-R1, VEGF-R2, and VEGF-R3 in melanoma tissue microarrays. Hum Pathol 41: 375-384, 2010.

54. Jiang CC, Lai F, Thorne RF, Yang F, Liu H, Hersey P and Zhang XD: MEK-independent survival of B-RAFV600E melanoma cells selected for resistance to apoptosis induced by the RAF inhibitor PLX4720. Clin Cancer Res 17: 721-730, 2011.

55. Shi H, Kong X, Ribas A and Lo RS: Combinatorial treatments that overcome PDGFR $\beta$-driven resistance of melanoma cells to V600EB-RAF inhibition. Cancer Res 71: 5067-5074, 2011.

56. Atefi M, von Euw E, Attar N, Ng C, Chu C, Guo D, Nazarian R, Chmielowski B, Glaspy JA, Comin-Anduix B, et al: Reversing melanoma cross-resistance to BRAF and MEK inhibitors by co-targeting the AKT/mTOR pathway. PLoS One 6: e28973, 2011.

57. Su F, Bradley WD, Wang Q, Yang H, Xu L, Higgins B, Kolinsky K, Packman K, Kim MJ, Trunzer K, et al: Resistance to selective BRAF inhibition can be mediated by modest upstream pathway activation. Cancer Res 72: 969-978, 2012

58. Lassen A, Atefi M, Robert L, Wong DJ, Cerniglia M, CominAnduix B and Ribas A: Effects of AKT inhibitor therapy in response and resistance to BRAF inhibition in melanoma. Mol Cancer 13: 83, 2014. 